\title{
Pengaruh Terapi Yoga (Paschimottanasana dan Adho Mukha Padmasana) terhadap Intensitas Nyeri pada Remaja Putri yang Mengalami Dismenore Primer
}

\section{The Effect of Yoga Therapy (Paschimottanasana and Adho Mukha Padmasana) on Pain Intensity in Adolescence Girls Experiencing Primary Dysmenorrhea}

R. Tri Rahayuning Lestari ${ }^{1}$, Ni Made Nopita Wati ${ }^{1}$, I Gede Juanamasta ${ }^{1}$, Ni Luh Putu Thrisnadewi ${ }^{1}$, Ni Komang Ayu Sintya Paramita ${ }^{1}$

1) STIKes Wira Medika Bali, Indonesia

\author{
tri515@gmail.com
}

DOI: http://doi.org/10.29080/jhsp.v3i2.221

Received: August 2019, Accepted: August 2019, Published: September 2019

\section{Kata Kunci}

Yoga

Dismenore

Remaja

\section{Abstrak}

Dismenore primer merupakan nyeri menstruasi yang sering mengganggu aktivitas pada remaja putri, sehingga diperlukan upaya untuk mengatasinya. Yoga merupakan salah satu cara non farmakologi untuk mengatasi nyeri dismenorhea. Penelitian ini bertujuan untuk mengetahui Pengaruh Terapi Yoga (Paschimottanasana dan Adho Mukha Padmasana) terhadap Intensitas Nyeri pada Remaja Putri yang mengalami Dismenore Primer di SMPN 3 Mengwi. Jenis penelitian ini adalah quasi eksperiment dengan rancangan pretest-posttest with control group design. Pengambilan sampel dengan teknik porpusive sampling sebanyak 28 orang siswi (14 kelompok kontrol, 14 kelompok perlakuan). Instrumen pengumpulan data menggunakan Verbal Descriptor Scale. Hasil uji Shapiro-Wilk diperoleh $\mathrm{p}=0,061>0,05$ yang bermakna data berdistribusi normal Hasil uji Paired T-Test pada kelompok perlakuan menunjukan terdapat perbedaan yang signifikan sebelum dan sesudah diberikan yoga dengan nilai $p=<0,001$ maka $p<0,05$, hasil pada kelompok kontrol tidak terdapat perbedaan yang signifikan sebelum dan sesudah dengan nilai $\mathrm{p}=0,583>0,05$. Hasil uji Independent T-Test menunjukan terdapat Pengaruh Terapi Yoga (Paschimottanasana dan Adho Mukha Padmasana) terhadap Intensitas Nyeri pada Remaja Putri yang Mengalami Dismenore Primer dengan nilai $\mathrm{p}=0,001<0,05$. Berdasarkan penelitian ini, terapi yoga (Paschimottanasana dan Adho Mukha Padmasana) dapat digunakan sebagai manajemen non farmakologi untuk mengurangi nyeri dismenore pada remaja putri.

\section{Keywords}

Yoga

Dysmenorrhea

Adolescence

\begin{abstract}
Primary dysmenorrhea is a menstrual pain are disturbed the activity of adolescence girls, so efforts are needed to overcome them. Yoga is one of the non-pharmacological ways to overcome the pain of dysmenorrhea. This study aims to determine the effect of Yoga Therapy (Paschimottanasana and Adho Mukha Padmasana) on Pain Intensity in Adolescence girls Who Experienced Primary Dysmenorrhea at SMPN 3 Mengwi. This type of research is quasi experiment with pretest-posttest with control group design. Sampling using porpusive sampling technique was 28 students (14 control groups, 14 treatment groups). The data collection instrument uses Verbal Descriptor Scale. Shapiro-Wilk test results obtained $p=0.061>0.05$ which means normal distributed data. The result of Paired T-Test in the treatment group showed that there was significant difference before and after given yoga with $p=<0.001$ then $p<0,05$, the result in control group there was no significant difference before and after $p=0,583>0.05$. The results of the Independent $T$ Test showed that there is Influence of Yoga Therapy (Paschimottanasana and Adho Mukha Padmasana) on Pain Intensity in Adolescence girls who experienced Primary Dysmenorrhea with $p=0,001<0,05$. Based on this research, yoga therapy (Paschimottanasana and Adho Mukha Padmasana) can be used as non-pharmacological management to reduce dysmenorrheal pain in adolescence girls.
\end{abstract}




\section{Pendahuluan}

Masa remaja disebut juga sebagai masa perubahan, meliputi perubahan dalam sikap, dan perubahan fisik [1]. Masa ini terjadi suatu fase perkembangan yang dinamis dalam kehidupan seorang individu, dimana salah satu tanda yang khas pada remaja adalah terjadinya pubertas. Pubertas didefinisikan sebagai waktu kematangan seksual yang ditandai dengan adanya menarche (menstruasi pertama kali) yang merupakan salah satu tanda terjadinya masa reproduksi pada anak perempuan. Gangguan menstruasi yang sering dialami oleh wanita adalah dismenore dan amenore [2]. Dismenore berarti nyeri saat menstruasi. Ada dua tipe dismenore yaitu dismenore primer dan sekunder. Dismenore primer adalah nyeri haid yang dijumpai tanpa kelainan pada alat-alat genital yang nyata.

Dismenore dialami lebih dari 50\% wanita yang sedang menstruasi dan prevalensi yang dilaporkan sangat bervariasi yakni berkisar 45-95\% [3]. Rata-rata lebih dari 50\% perempuan di setiap negara mengalami dismenore. Angka presentase di Amerika sekitar 60\% dan di Swedia sekitar 72\% mengalami dismenore. Angka kejadian dismenorea tipe primer di Indonesia adalah sekitar 54,89\% dan dismenore tipe sekunder sebesar 9,36\% [4]. Angka kejadian dismenore menurut Dinas Kesehatan Provinsi Bali tahun 2014 sebanyak 48,05\% [5]. Nyeri haid mengganggu wanita dalam beraktivitas, menyebabkan para wanita berupaya mencari cara untuk mengurangi nyeri yang dialaminya. Cara mengurangi nyeri haid dapat dilakukan dengan dua cara yaitu farmakologi dan non farmakologi. Cara farmakologi dengan minum obatobatan dan cara non farmakologi dapat dilakukan dengan kompres hangat atau mandi air hangat, massage, latihan fisik (exercise), tidur yang cukup, distraksi seperti mendengarkan musik serta relaksasi seperti yoga [6]. Cara farmakologi memang memiliki efek yang instan dan lebih efektif dalam mengurangi nyeri haid yang dialami wanita daripada cara non farmakologi, namun bila mengonsumsi obat-obatan dalam jangka waktu yang panjang akan berdampak negative bagi kesehatan seperti terjadi kerusakan pada hati dan ginjal.

Salah satu cara non farmakologis yang dapat dilakukan untuk mengurangi nyeri saat haid dan tidak memiliki efek negative adalah yoga [7]. Terapi yoga merupakan salah satu teknik relaksasi yang dianjurkan untuk mengurangi tingkat dismenorea. Pelatihan yang terarah dan berkesinambungan dipercaya mampu menyembuhkan nyeri haid dan menyehatkan badan secara keseluruhan. Posisi yoga yang dilakukan ketika sedang menstruasi haruslah merilekskan tubuh, tidak mengganggu arah sirkulasi darah yang harus turun ke bawah dan keluar, tidak terlalu banyak menghabiskan tenaga dan tidak menimbulkan gangguan pada hormone. Beberapa posisi yoga yang dianjurkan untuk meringankan nyeri saat menstruasi adalah paschimottanasana dan adho muka padmasana [7].

Data menunjukkan terdapat sekitar 67.237 orang remaja pada tahun 2012 di Kabupaten Badung. Data KEMDIKBUD pada tahun pelajaran 2017/2018 SMPN 3 Mengwi memperoleh siswa sebanyak 1549 orang dimana jumlah tersebut lebih banyak dari jumlah siswa yang diperoleh oleh SMPN lainnya yang ada di Kecamatan Mengwi [8]. Studi pendahuluan yang dilakukan pada siswi kelas VIII di SMPN 3 Mengwi pada tanggal 22 Februari 2018, total remaja putri 268 siswi, terdapat 152 siswi mengalami nyeri saat haid. Gejala lain yang dirasakan oleh siswi antara lain nyeri pada payudara, perubahan mood, nyeri pinggang, mudah lelah, mual dan penurunan stamina. Penanganan yang dilakukan oleh para remaja putri juga berbeda-beda antara lain mengonsumsi obat penghilang nyeri, hanya tidur di UKS, mengoleskan minyak kayu putih/ aromatherapy, dan banyak mengonsumsi air putih, tetapi belum ada yang melakukan penanganan dismenorea dengan terapi yoga. Berdasarkan hal tersebut peneliti merasa perlu untuk melakukan penelitian untuk menganalisis Pengaruh Terapi Yoga (Paschimottanasana dan Adho Mukha Padmasana) Terhadap Intensitas Nyeri Pada Remaja Putri yang Mengalami Dismenore Primer di SMPN 3 Mengwi.

\section{Metode Penelitian}

Penelitian ini adalah penelitian kuantitatif dengan jenis penelitian Quasi eksperiment yaitu upaya untuk mengungkapkan hubungan sebab akibat dengan cara melibatkan kelompok kontrol di samping kelompok eksperimental. Rancangan yang digunakan adalah Pretest-Postest With Control Group Design. Teknik pengambilan sampel pada penelitian ini menggunakan non probability sampling, yaitu porpusive sampling. Sampel penelitian ini adalah 152 siswi kelas VIII di SMPN 3 Mengwi dengan kriteria inklusi yaitu siswi yang berumur 13-15 tahun dan mengalami menstruasi, disminore primer, bersedia menjadi responden serta melakukan gerakan yoga. Sampel dalam penelitian ini sebanyak 28 orang (14 orang kelompok kontrol dan 14 orang kelompok perlakuan). Instrumen yang dipergunakan dalam penelitian ini adalah pengukuran intensitas nyeri haid dengan menggunakan Verbal Descriptor Scale/ VDS. Data yang diperoleh dilakukan uji normalitas menggunakan uji Shapiro Wilk, diperoleh p=0,061 maka p>0,05 yang berarti data berdistribusi normal, sehingga pretest dan posttest baik pada kelompok eksperimen maupun kelompok kontrol diuji menggunakan paired sample t-test dan uji independent sample t-test. 


\section{Hasil Penelitian}

Analisa deskriptif didapatkan sebagian besar responden berusia 14 tahun pada kelompok kontrol sedangkan pada kelompok perlakukan sebagain besar responden berusia 13 tahun. Usia menarche didapatkan sebagian besar responden pada kelompok kontrol memasuki usia 13 tahun sedangkan pada kelompok perlakukan memasuki usia 12 tahun.

Tabel 1. Karakteristik Responden

\begin{tabular}{|c|c|c|c|c|c|}
\hline \multirow[b]{2}{*}{ Kelompok } & \multirow[b]{2}{*}{ Usia } & \multicolumn{4}{|c|}{ Karakteristik } \\
\hline & & & $\begin{array}{c}\text { Usia } \\
\text { Frekuensi (\%) }\end{array}$ & & $\begin{array}{l}\text { Usia Menarche } \\
\text { Frekuensi (\%) }\end{array}$ \\
\hline \multirow[t]{4}{*}{ Perlakuan } & 11 & & & 2 & $(14,3 \%)$ \\
\hline & 12 & & & 8 & $(57,1 \%)$ \\
\hline & 13 & 8 & $(57,1 \%)$ & 3 & $(21,4 \%)$ \\
\hline & 14 & 6 & $(42,9 \%)$ & 1 & $(7,2 \%)$ \\
\hline Total & & 14 & $(100 \%)$ & 14 & $(100 \%)$ \\
\hline \multirow[t]{4}{*}{ Kontrol } & 12 & & & 5 & $(35,7 \%)$ \\
\hline & 13 & 3 & $(21,4 \%)$ & 9 & $(64,3 \%)$ \\
\hline & 14 & 10 & $(71,45)$ & & \\
\hline & 15 & 1 & $(7,2 \%)$ & & \\
\hline Total & & 14 & $(100 \%)$ & 14 & $(100 \%)$ \\
\hline
\end{tabular}

Sumber: Data Primer, 2019.

Table 2. Hasil Sebelum dan Sesudah Terapi pada Kelompok Perlakuan dan Kontrol

\begin{tabular}{|c|c|c|c|c|c|}
\hline \multirow{2}{*}{$\begin{array}{l}\text { Variabel } \\
\text { Intensitas Nyeri Kelompok Perlakuan }\end{array}$} & \multirow{2}{*}{$\begin{array}{c}\text { Skala Nyeri } \\
2\end{array}$} & \multicolumn{2}{|c|}{$\begin{array}{c}\text { Pre } \\
\text { Frekuensi }(\%) \\
\end{array}$} & \multicolumn{2}{|c|}{$\begin{array}{c}\text { Post } \\
\text { Frekuensi }(\%)\end{array}$} \\
\hline & & & & 2 & $(14,3 \%)$ \\
\hline & 3 & 3 & $(21,4 \%)$ & 9 & $(64,3 \%)$ \\
\hline & 4 & 4 & $(42,9 \%)$ & 2 & $(14,3 \%)$ \\
\hline & 5 & 5 & $(21,4 \%)$ & 1 & $(7,1 \%)$ \\
\hline & 6 & 6 & $(14,3 \%)$ & & \\
\hline Total & & 14 & $(100 \%)$ & 14 & $(100 \%)$ \\
\hline \multirow{5}{*}{ Intensitas Nyeri Kelompok Kontrol } & 2 & 2 & $(14,3 \%)$ & 1 & $(7,1 \%)$ \\
\hline & 3 & 3 & $(21,4 \%)$ & 6 & $(43 \%)$ \\
\hline & 4 & 5 & $(35,7 \%)$ & 3 & $(21,4 \%)$ \\
\hline & 5 & 3 & $(21,4 \%)$ & 3 & $(21,4 \%)$ \\
\hline & 6 & 1 & $(7,2 \%)$ & 1 & $(7,1 \%)$ \\
\hline Total & & 14 & $(100 \%)$ & 14 & $(100 \%)$ \\
\hline
\end{tabular}

Sumber: Data Primer, 2019

Table 3. Hasil Uji Sebelum dan Sesudah Terapi pada Kelompok Perlakuan dan Kontrol

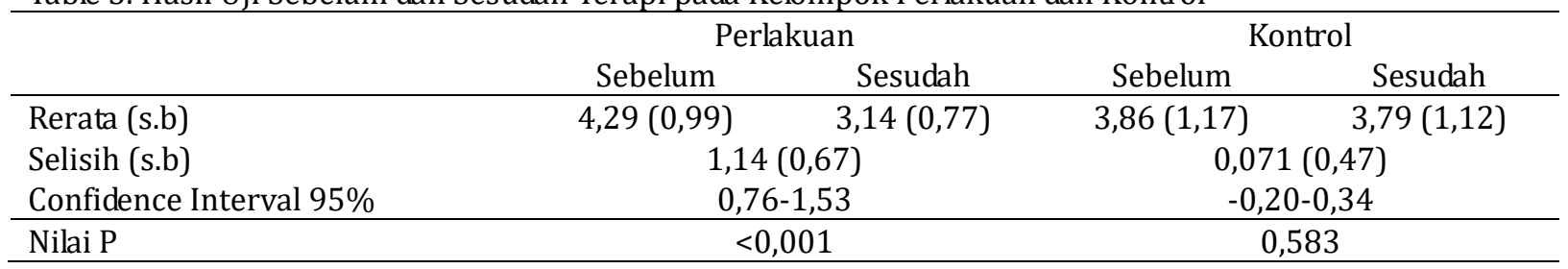

Sumber: Data Primer, 2019

Tabel 4. Hasil antara Kelompok Perlakuan dan Kontrol

\begin{tabular}{lcc}
\hline & Perlakuan & Kontrol \\
\hline Rerata (s.b) & $3,14(0,77)$ & $4,36(1,01)$ \\
Confidence Interval 95\% & $1,22(0,517-1,911)$ \\
\hline Nilai P & 0,001 \\
\hline Sumber
\end{tabular}

Sumber: Data Primer, 2019.

Analisis bivariat pada tabel 3. terkait (Yoga Paschimottanasana dan Adho Mukha Padmasana) didapatkan hasil $p$ value $=<0,001$ maka $p<0,05$, sehingga dapat disimpulkan terdapat perbedaan rata-rata intensitas nyeri disminore yang signifikan sebelum dan sesudah terapi yoga pada kelompok perlakuan. Sedangkan nilai p value pada kelompok kontrol yaitu 0,583>0,05 sehingga dapat disimpulkan tidak terdapat perbedaan rata-rata intensitas nyeri disminore yang signifikan sebelum dan sesudah pada kelompok kontrol. 
Hasil uji analisis uji beda rata-rata Independent $T$ Test pada tabel 4. didapatkan hasil $\mathrm{p}=0,001<0,05$ yang bermakna terdapat perbedaan rata-rata intensitas nyeri yang signifikan antara kelompok perlakuan dengan intensitas nyeri pada kelompok kontrol (tanpa terapi yoga). Sehingga dapat disimpulkan terdapat pengaruh terapi yoga (Paschimottanasana dan Adho Mukha Padmasana) terhadap intensitas nyeri pada remaja putri yang mengalami disminore primer di SMP Negeri 3 Mengwi.

\section{Pembahasan}

Hasil penelitian intensitas nyeri yang ditemukan sebelum diberikan terapi yoga yaitu sebagian besar intensitas nyeri pada kelompok perlakuan berada pada skala 4 nyeri sedang yaitu sebanyak 42,9\%, sedangkan pada kelompok kontrol sebagian besar responden intensitas nyerinya berada pada skala 4 nyeri sedang yaitu sebanyak 35,7\%. Penelitian ini sesuai dengan penelitian yang dilakukan oleh Indrawijaya [10] menunjukkan bahwa 47,06\% dengan kategori sebagian responden mengalami nyeri sedang. Penelitian Siahaan [11] menunjukan hasil penelitian tingkat dismenore sebelum dilakukan yoga $50 \%$ responden mengalami dismenore dengan kategori nyeri sedang, dan $10 \%$ mengalami nyeri berat tertahankan.

Berdasarkan karakteristik umur responden di dalam penelitian ini didapatkan hasil bahwa sebagian besar kelompok kontrol dan kelompok perlakuan berusia pada rentang 13 sampai usia 14 tahun dan usia menarch atau menstruasi pertama pada kelompok kontrol dan kelompok perlakuan berkisar antara 12 hingga 13 tahun. Berdasarkan karakteristik umur responden dan usia menarch (menstruasi pertama) menurut hasil penelitian Indah [12] dismenore pada umumnya terjadi 2 sampai 3 tahun setelah menarch atau idealnya pada usia 12-15 tahun. Hasil ini juga sejalan dengan penelitian di Makasar bahwa semakin cepat usia menarch pada seorang perempuan akan meningkatkan nyeri saat menstruasi [13]. Nyeri yang dirasakan pada perut bagian bawah yang bisa menjalar ke punggung bagian bawah dan tungkai. Nyeri yang dirasakan seperti kram hilang timbul atau nyeri tumpul yang dirasakan terus menerus. Nyeri yang dialami remaja sebelum diberikan terapi yoga diakibatkan karena adanya peningkatan produksi hormone prostaglandin sehingga mengakibatkan hiperaktivitas uterus [14]. Dismenore biasanya terjadi akibat pelepasan berlebihan prostaglandin tertentu yaitu Prostaglandin - F2 alfa, dari sel sel endometrium uterus. Prostaglandin - F2 alfa adalah suatu perangsang kuat kontraksi otot polos miometrium dan konstriksi pembuluh darah uterus. Hal ini memperparah hipoksia uterus yang secara normal terjadi pada haid, sehingga timbul rasa nyeri hebat [15]. Prostaglandin juga merangsang kontraksi ritmik ringan miometrium uterus. Kontraksi ini membantu mengeluarkan darah dari vagina sebagai darah haid. Kontraksi uterus yang terlalu kuat akibat produksi berlebihan prostaglandin menyebabkan kram haid (dismenore) yang dialami remaja. Menurut Widjanarko (2006) dalam Sartika [16] terdapat hubungan antara usia menarch dan nyeri dismenore dimana bila menarch terjadi lebih awal dari normal maka alat reproduksi belum siap untuk mengalami perubahan dan masih terjadi penyempitan pada leher rahim, sehingga akan timbul rasa sakit pada saat menstruasi. Hasil dari identifikasi terhadap objek penelitian dan teori tentang dismenore pada remaja putri sebelum diberikan perlakuan yoga, intensitas nyeri haid yang kebanyakan diderita oleh remaja putri adalah dengan intensitas nyeri sedang yaitu dalam rentang 4-6 dimana nyeri tersebut dirasakan karena adanya produksi prostaglandin yang berlebihan pada responden.

Berdasarkan hasil penelitian setelah diberikan terapi, skala nyeri sebagian besar menjadi $3(64,3 \%)$ sedangkan pada kelompok kontrol skala nyeri sebagian besar juga menjadi 3 (43\%) namun dengan frekuensi yang berbeda. Penelitian ini sesuai dengan penelitian Purnaningsih dan Mursudarinah [17] yang menunjukan bahwa setelah diberikan intervensi, intensitas nyeri responden berkurang dari nyeri sedang menjadi nyeri ringan. Penelitian lain yang sesuai dengan penelitian ini adalah penelitian Siahaan [11] dimana diperoleh hasil sebelum diberikan yoga didapatkan sebanyak 50\% responden mengalami nyeri sedang, 10\% mengalami nyeri berat terkontrol, sedangkan setelah diberikan terapi yoga $70 \%$ responden mengalami nyeri ringan, 15\% tidak mengalami nyeri. Olahraga merupakan salah satu manajemen non farmakologis yang lebih aman digunakan karena menggunakan proses fisiologis. Hal ini disebabkan karena saat melakukan olahraga tubuh akan menghasilkan endorphin. Hal ini sesuai dengan teori Gate Control yang dikemukan oleh Wall, bahwa implus nyeri dihantarkan saat sebuah pertahanan dibuka dan impuls dihambat saat sebuah pertahanan tertutup. Upaya menutup pertahanan tersebut merupakan dasar terapi untuk menghilangkan nyeri. Pemblokan ini dapat dilakukan melalui mengalihkan perhatian ataupun dengan tindakan relaksasi. Dari identifikasi terhadap obyek penelitian dan teori tentang nyeri haid pada remaja putri, peneliti menyimpulkan bahwa memang benar setelah diberikan intervensi intensitas nyeri yang diderita oleh remaja putri berkurang skalanya menjadi rata-rata nyeri ringan yaitu dalam rentang 2-5, namun terdapat pula responden yang tidak mengalami penurunan nyeri atau intensitas nyeri setelah dilakukan yoga masih tetap sama dengan sebelum diterapi yoga. Hal ini terjadi karena responden tersebut jarang melakukan olahraga dan pada saat melakukan yoga, gerakannya 
kurang maksimal sehingga hal tersebut dapat mempengaruhi intensitas nyeri yang dirasakan oleh responden.

Hasil penelitian ini menunjukkan bahwa berdasarkan uji Paired $T$ Test terkait (Yoga Paschimottanasana dan Adho Mukha Padmasana) didapatkan hasil $\mathrm{p}$ value $=<0,001$ yaitu $\mathrm{p}<0,05$, sehingga dapat disimpulkan terdapat perbedaan rata-rata intensitas nyeri dismenorhea yang signifikan sebelum dan sesudah diberikan terapi yoga (Paschimottanasana dan Adho Mukha Padmasana) pada kelompok perlakuan, sedangkan nilai $p$ value pada kelompok kontrol yaitu $0,583>0,05$ sehingga dapat disimpulkan tidak terdapat perbedaan rata-rata intensitas nyeri disminore yang signifikan sebelum dan sesudah pada kelompok kontrol.

Hasil penelitian ini didukung dengan hasil penelitian sebelumnya yang dilakukan oleh Purnaningsih dan Mursudarinah [17] dimana didapatkan hasil $p(0,000)<\alpha(0,05)$ setelah diberikan perlakuan yoga, sehingga dapat disimpulkan ada pengaruh signifikan senam yoga terhadap pengurangan rasa nyeri disminore pada remaja di SMK N 1 Karanganyar. Secara konsep, perubahan intensitas nyeri pada kelompok perlakuan menjadi menurun diperkuat oleh teori yang dijelaskan oleh Ernawati dan Idris [18] bahwa efek relaksasi dari yoga memberikan individu kontrol diri ketika terjadi rasa tidak nyaman atau nyeri, stres fisik, emosi serta menstimulus pelepasan endorfin dapat meningkatkan respons saraf parasimpatis yang mengakibatkan vasodilatasi pembuluh darah seluruh tubuh dan uterus sehingga mengurangi intensitas nyeri disminorea.

Terapi yoga merupakan salah satu teknik relaksasi yang dianjurkan untuk mengurangi tingkat dismenorea. Pelatihan yang terarah dan berkesinambungan dipercaya mampu menyembuhkan nyeri haid dan menyehatkan badan secara keseluruhan. Manfaat berlatih yoga diantaranya, meningkatkan sirkulasi darah keseluruh tubuh, meningkatkan kapasitas paru saat bernafas, mengurangi ketegangan tubuh, fikiran dan mental, serta mengurangi rasa nyeri. Yoga juga dipercaya dapat mengurangi cairan yang menumpuk di bagian pinggang yang menyebabkan nyeri saat haid [7]. Menurut peneliti, yoga sangat membantu pengurangan nyeri pada remaja yang mengalami dismenorea karena yang diberikan yoga akan merasakan rileks dan mengurangi kram atau kontraksi pada abdomen. Efek dari relaksasi ini akan meningkatkan respon saraf parasimpatis yang mengakibatkan vasodilatasi pembuluh darah uterus sehingga aliran darah uterus meningkat dan kontraksi berkurang. Pemberian yoga ini juga memberikan stimulus mekanoreseptor pada kulit abdomen sehingga memberikan relaksasi otot abdomen yang dirasakan menjadi berkurang. Dari hal tersebutlah dapat disimpulkan bahwa pemberian yoga berpengaruh dengan intensitas nyeri pada saat menstruasi.

Berdasarkan uji Independent $T$ Test pada kedua kelompok didapatkan hasil rata-rata tingkat nyeri disminore pada kelompok perlakuan (Yoga Paschimottanasana dan Adho Mukha Padmasana) lebih rendah sebesar 1,22 dibandingkan dengan intensitas nyeri pada kelompok tanpa pemberian yoga. Selanjutnya pada nilai $\mathrm{p}$ didapatkan hasil $0,001<0,05$ yang bermakna terdapat perbedaan rata-rata intensitas nyeri yang signifikan antara kelompok perlakuan (Yoga Paschimottanasana dan Adho Mukha Padmasana) dengan intensitas nyeri pada kelompok kontrol (tanpa terapi yoga), sehingga dapat disimpulkan terdapat pengaruh terapi yoga (Paschimottanasana dan Adho Mukha Padmasana) terhadap intensitas nyeri pada remaja putri yang mengalami dismenorea. Penelitian ini sejalan dengan hasil penelitian sebelumnya yang dilakukan oleh Manurung [19] bahwa hasil perbandingan intensitas nyeri sesudah antara kelompok eksperimen yang diberikan perlakuan dengan kelompok kontrol yang tidak diberikan perlakuan menunjukkan nilai p-value 0,000 nilai $p$-value $<\alpha(0,05)$, artinya yoga efektif dalam menurunkan intensitas nyeri dismenore. Teori juga menyatakan bahwa yoga merupakan salah satu cara untuk membantu menurunkan skala nyeri pada saat menstruasi. Yoga sangat membantu pengurangan nyeri terutama nyeri bagian sensori dan emosional yang tidak menyenangkan sebagai akibat dari kerusakan jaringan yang aktual dan potensial yang menyakitkan tubuh serta diungkapkan oleh individu yang mengalaminya.

Posisi yoga yang dilakukan ketika sedang menstruasi haruslah merilekskan tubuh dan pilihlah posisiposisi yang tidak mengganggu arah sirkulasi darah yang harus turun ke bawah dan keluar, tidak terlalu banyak menghabiskan tenaga dan tidak menimbulkan gangguan pada hormone. Posisinya haruslah yang dapat meringankan nyeri dan mengatasi stress, kecemasan dan depresi yang diakibatkan oleh menstruasi. Posisi yoga untuk menstruasi ini lebih banyak berkonsentrasi untuk membuka pinggul, tulang panggul, punggung bawah dan kaki, merilekskan perut dan rahim. Hal ini agar bagian-bagian tersebut dapat disuplai dengan aliran tenaga, nutrisi, dan darah segar. Posisinya hampir semua dengan keadaan duduk dan melipat ke depan yang bisa membuat para perempuan bernapas lebih dalam lagi sambil melepaskan segala ketegangan di perut dan punggung bawah sehingga tenaga dan aliran darahnya bisa mengalir lebih lancar [7].

Gerakan yoga Paschimottanasana dan Adho Mukha Padmasana merupakan dua gerakan dari beberapa gerakan yoga yang posisinya tidak mengganggu arah sirkulasi darah yang harus turun ke bawah dan keluar, tidak terlalu banyak menghabiskan tenaga dan gerakannya dilakukan dengan keadaan duduk dan 
melipat ke depan yang mampu mengurangi nyeri saat menstruasi. Selain dapat menghilangkan ketidaknyamanan selama menstruasi, gerakan Paschimottanasana memiliki manfaat untuk menguatkan kaki, bahu, dan punggung, mengencangkan otot perut, melancarkan pencernaan, menguatkan organ tubuh bagian dalam, menenangkan tubuh, menghilangkan sakit kepala, stress, depresi ringan, kecemasan, kelelahan, menghilangkan gejala menopause, merangsang system reproduksi, menjadi terapi yang baik untuk tekanan darah tinggi, ketidaksuburan pada kandungan, susah tidur, sinus dan mengurangi obesitas, gerakan ini juga berguna untuk meregangkan tulang punggung. Gerakan yoga yang kedua yaitu Adho Mukha Padmasana (posisi wajah menghadap ke bawah dari posisi duduk teratai). Gerakan yoga ini selain membantu mengurangi nyeri pada saat menstruasi, gerakan ini juga bermanfaat untuk menguatkan otot kaki, mengencangkan pinggul dan memijat bagian paha serta pergelangan kaki, memanjangkan sisi badan, melatih bahu dan merilekskan pikiran serta perut (5). Dilihat dari hasil penelitian di atas dan teori yang mendukung, peneliti menarik kesimpulan bahwa pemberian terapi yoga (Paschimottanasana dan Adho Mukha Padmasana) berpengaruh terhadap intensitas nyeri pada remaja putri yang mengalami dismenore primer karena yoga tersebut mampu memberikan efek relaksasi yang dapat menstimulus pelepasan endorfin dan dapat meningkatkan respons saraf parasimpatis yang mengakibatkan vasodilatasi pembuluh darah seluruh tubuh dan uterus sehingga mengurangi intensitas nyeri disminorea.

\section{Simpulan dan Saran}

Terapi yoga (Paschimottanasana dan Adho Mukha Padmasana) memiliki pengaruh yang signifikan dalam menurunkan intensitas nyeri pada remaja putri yang mengalami dismenorea. Bagi tenaga kesehatan agar dapat mempertimbangkan intervensi terapi yoga (Paschimottanasana dan Adho Mukha Padmasana) sebagai tindakan alternative dalam menurunkan nyeri saat menstruasi dan diharapkan tenaga kesehatan khususnya di Puskesmas agar menjalin kerjasama dengan pihak sekolah mengenai pendidikan kesehatan reproduksi remaja khususnya tentang dismenore. Bagi masyarakat khususnya remaja putri diharapkan agar menggunakan yoga untuk menangani nyeri dismenorea dan menghindari penggunaan teknik farmakologi untuk penanganan nyeri dismenorea.

Peneliti selanjutnya diharapkan untuk dapat melaksanakan penelitian lebih lanjut dengan variabel dan analisis yang berbeda serta dapat mengembangkan wilayah penelitian tidak hanya di satu kecamatan saja, serta dapat mengembangkan ketersediaan dan efektivitas mekanisme non farmasi dalam mengatasi dismenore.

\section{Daftar Pustaka}

1. Pratiwi RY. Kesehatan remaja di Indonesia. Dalam http//www idai or id/artikel/seputar-kesehatananak/kesehatan-remaja-di-indonesia Diakses pada. 2018;5.

2. Lubis N. Psikologi Kespro: Wanita \& Perkembangan Reproduksinya Ditinjau dari Aspek Fisik dan Psikologinya. Jakarta: Kencana Prenada Media Group; 2013.

3. Iacovides S, Avidon I, Baker FC. What we know about primary dysmenorrhea today: a critical review. Hum Reprod Update. 2015;21(6):762-78.

4. Husain 0. Hubungan Pengetahuan Tentang Dismenore Dengan Upaya Penanganannya Pada Siswi Kelas X di SMK Negeri 1 Batudaa. Universitas Negeri Gorontalo; 2014.

5. Dinas Kesehatan Provinsi Bali. Angka Kejadian Dismenore. Denpasar; 2014.

6. Judha M, Sudarti FA. Teori pengukuran nyeri dan nyeri persalinan. Jogjakarta, Muha Med. 2012;

7. Amalia A. Tetap Sehat Dengan Yoga. Jakarta: Panda Medika; 2015.

8. Kementerian Pendidikan dan Kebudayaan. Data Siswa SMPN 3 Mengwi Tahun Pelajaran 2017/2018. Jakarta; 2017.

9. Nursalam. Metodologi Penelitian Ilmu Keperawatan: Pendekatan Praktis. Jakarta: Salemba Medika; 2013.

10. Indrawijaya R, Maryati I, Dirgahayu N. Pengaruh Gerakan Yoga Janusirsasana Terhadap Tingkat Nyeri Saat Menstruasi Pada Remaja Putri di Sekolah Menengah Atas Al Musdariyah Reysha Indrawijaya, Ida Maryati , Inggrid Dirgahayu. Bhakti Kencana Med. 2012;2(4).

11. Siahaan K. Penurunan Tingkat Dismenore pada Mahasiswi Fakultas Ilmu Keperawatan UNPAD dengan Menggunakan Yoga. Students e-Journal. 2012;1(1):30.

12. Astria I, Utami S, Utomo W. Efektifitas Kombinasi Teknik Slow Deep Breathing Dan Teknik Effleurage Terhadap Intensitas Nyeri. JOM. 2015;2(2).

13. Beddu S, Mukarramah S, Lestahulu V. Hubungan Status Gizi dan Usia Menarche dengan Dismenorea Primer pada Remaja Putri. Southeast Asian J Midwifery. 2015;1 No.1.

14. Potter PA, Perry AG, Stockert P, Hall A. Fundamentals of Nursing - E-Book. St. Louis, Missouri: Elsevier Health Sciences; 2016. 
15. Corwin EJ. Buku Saku Patofisiologi Corwin. Jakarta: Egc; 2009.

16. Sartika S. Hubungan Status Gizi Dan Usia Menarche Terhadap Dismenore Primer Pada Siswi Kelas IX SMPN 87 Jakarta tahun 2011. Universitas Pembangunan Nasional Veteran Jakarta; 2011.

17. Purnaningsih E, Mursudarinah. Penguh Senam Yoga terhadap Tingkat Nyeri Dismenore pada Remaja di SMKN 1 Karanganyar. J kebidanan dan ilmu Kesehat. 2016;3(3).

18. Ernawati H, Idris H. Terapi Relaksasi terhadap Nyeri Dismenore pada Mahasiswi Universitas Muhammadiyah Semarang. Pros Semin Nasioanal UNIMUS. 2010;106-13.

19. Manurung MF, Rahmalia HD. Efektivitas Yoga Terhadap Nyeri Dismenore Pada Remaja. J Online Mhs Progr Stud Ilmu Keperawatan Univ Riau. 2015;2(2):1258-65. 